\title{
RESUMO
}

\section{A CONSTRUÇÃO DO CONHECIMENTO CIENTÍFICO NA BASE NACIONAL COMUM CURRICULAR}

\section{CONSTRUCTION OF SCIENTIFIC KNOWLEDGE IN THE CURRICULAR COMMON NATIONAL BASIS}

CONSTRUCCIÓN DEL CONOCIMIENTO CIENTÍFICO

EN LA BASE NACIONAL COMÚN CURRICULAR
Flávia Pierrotti de Castro ${ }^{1}$ Marcos César Rodrigues de Miranda ${ }^{2}$

Renan Antônio da Silva ${ }^{3}$

Rosebelly Nunes Marques ${ }^{4}$
O objetivo deste artigo foi identificar quais competências gerais da Base Nacional Comum Curricular (BNCC) asseguram a construção do conhecimento científicod e forma contextualizada. Seu percurso metodológico se deu por meio da Análise textual dividida em três etapas: leitura e reflexão do marco legal da BNCC; análise das dez competências gerais e interpretação das mesmas para construção de seus significados. Foram identificadas seis competências gerais que apresentam a construção do conhecimento científico de forma dinâmica, contextualizada e histórica, visando a formação integral e humana dos discentes brasileiros.

\section{PALAVRAS-CHAVE}

Educação Básica. Formação Integral. Competências Cognitivas e Socioemocionais. 


\section{ABSTRACT}

The aim of this paper was to identify which general competences of the Common National Curriculum Base (BNCC, in Portuguese) ensure the construction of scientific knowledge in a contextualized way. Its methodological path was through textual analysis divided into three stages: reading and reflection of the BNCC legal framework; analysis of the ten general competences and interpretation of them to construct their meanings. Six general competences were identified that present the construction of scientific knowledge in a dynamic, contextualized and historical way, aiming at the integral and human formation of Brazilian students.

\section{KEYWORDS}

Basic Education. Integral Training. Cognitive and Socio-Emotional Skills

\section{RESUMEN}

El objetivo de este trabajo fue identificar qué competencias generales de la Base Nacional Común Curricular (BNCC) aseguran la construcción del conocimiento científico de manera contextualizada. Su camino metodológico fue a través del análisis textual dividido en tres etapas: lectura y reflexión del marco legal del BNCC; análisis de las diez competencias generales e interpretación de ellas para construir sus significados. Se identificaron seis competencias generales que presentan la construcción del conocimiento científico de forma dinámica, contextualizada e histórica, con el objetivo de la formación integral y humana de los estudiantes brasileños.

\section{PALABRAS CLAVE}

Educación básica, Formación Integral, Habilidades Cognitivas y Socioemocional 


\section{INTRODUÇ̧̃̃o}

O conhecimento científico é fruto do saber acumulado da experiência humana produzida a partir de modelos, análise de fatos reais e comprovados, para que o cidadão tenha uma visão real do mundo que o cerca e que saiba reconhecer, também interpretar fenômenos que ocorrem ao seu entorno, seja assertivo em suas decisões, dessa forma o conhecimento científico é parte da construção da cidadania e consequentemente de uma sociedade consciente de suas ações (GAGLIARDI, 1988; GAGLIARDI; GIORDAN, 1986, RODRÍGUEZ; ADÚRIZ-BRAVO; 2011, MATTHEWS, 1995 ).

Valorizar a construção do conhecimento científico contribui para uma melhor compreensão das Ciências na Educação Básica, pois atribui sentido e significado ao que deve ser ensinado e possibilita uma melhor compreensão do papel da ciência em nossa sociedade, portanto para o professor a concepção sobre as ciências pode fornecer subsídios para compreender melhor quais são as dificuldades conceituais dos estudantes. Nesse sentido é necessário pautar a organização dos conhecimentos e a prática docente no discurso dos documentos oficiais que regem a educação básica, em especial a atual Base Nacional Comum Curricular (BNCC).

A BNCC passou por muitas etapas para se tornar a referência do que atualmente deva ser ensinado nas escolas de todo o país, ela foi pautada em alguns marcos legais fazem parte de sua origem e constituição para que sua composição fosse sólida, já na promulgação da Constituição de 1988 é prevista uma base nacional comum, que tem como objetivo padronizar os conteúdos mínimos exigidos para o ensino fundamental, primeiro delas aparece na constituição de 1988: "Art. 210. Serão fixados conteúdos mínimos para o ensino fundamental, de maneira a assegurar formação básica comum e respeito aos valores culturais e artísticos, nacionais e regionais” (BRASIL, 1988, p.).

A Lei de Diretrizes, em 1996, permite possibilitar a garantia de que a educação seja oportunizada para todos de forma mais igualitária possível, preconizando uma base nacional comum, isso aparece em seu artigo 26

Art. 26. Os currículos da educação infantil, do ensino fundamental e do ensino médio devem ter base nacional comum, a ser complementada, em cada sistema de ensino e em cada estabelecimento escolar, por uma parte diversificada, exigida pelas características regionais e locais da sociedade, da cultura, da economia e dos educandos (BRASIL, 1996, p.)

As Diretrizes Nacionais Curriculares (DCN) apresentam as normas que são obrigatórias a serem seguidas no planejamento do currículo da educação básica, já os Parâmetros Curriculares Nacionais (PCN) que foram lançados respectivamente, Ensino Fundamental Anos Iniciais em 1997, Ensino Fundamental Anos Finais em 1998 e do Ensino Médio em 2000, elaboraram alguns parâmetros para 0 direcionamento do referencial comum do que deveria estar garantido no ensino, sem que houvesse uma uniformização e que a pluralidade cultural fosse ignorada.

Apesar dos PCN serem mais amplos eles acabam por integrar construção da base que em geral é mais específica em relação aos objetivos de aprendizagem em cada ciclo. 
Por fim o Plano Nacional de Educação que tem como objetivo estabelecer metas e estratégias para avanços significativos na educação, apresenta, especificamente nas metas 1, 2 e 3, pretende-se aumentar a porcentagem de matrículas nos diferentes níveis da educação básica, já na meta 7 o objetivo é aumentar a qualidade da educação, que é mensurada pelo cálculo do Índice de Desenvolvimento da Educação Básica (IDEB), a partir disso a BNCC é apresentada como estratégia para o alcance dessas metas.

Em setembro de 2015 sai a primeira versão da BNCC, já em março do ano seguinte ela vai para consulta pública on-line e com mais de 12 milhões de colaborações de diferentes setores da sociedade brasileira, em maio de 2016 sai a segunda versão, entre junho e agosto do mesmo ano ela passa em diversos seminários estaduais, com a participação de gestores, professores e alunos, em abril de 2017 sai a terceira versão, com o relatório revisado das duas versões anteriores ${ }^{5}$ com o objetivo de direcionar para o Conselho Nacional da Educação (CNE) os direitos e objetivos de aprendizagem para os estudantes da Educação Básica de todo o país, em acordo com Estados e Municípios para a adequação de seus currículos oficiais, em dezembro de 2017 a BNCC é homologada.

A BNCC apresenta um conjunto de aprendizagens essenciais para o desenvolvimento dos estudantes ao longo das etapas da Educação Básica, corroborando com a Lei de Diretrizes e Bases da Educação Nacional (LDB, Lei no 9394/2016) em que são indicados quais conhecimentos e competências espera-se da Educação Básica para que haja uma formação integral e humana, contribuindo para a construção de uma sociedade pautada na democracia, na justiça e na inclusão.

Este estudo teve por objetivo, identificar quais as competências e princípios que asseguram a construção do conhecimento científico de forma dinâmica, ampla, histórica e contextualizada, alinhados com a proposta de uma formação integral e humanizada dos estudantes na Base Nacional Comum Curricular.

\section{METODOLOGIA}

O presente estudo visou a análise textual (KNOBEL; LANKSHEAR, 2008) da Base Nacional Comum Curricular na busca de compreender e gerar significados para a construção do conhecimento científico presente neste documento.

O percurso metodológico consistiu em primeiro lugar: a leitura e reflexão sobre os marcos legais que embasaram a construção deste documento a fim de compreender sua origem e desdobramentos. Em segundo lugar: analisar as dez competências gerais que estruturam os Campos de Experiências da Educação Infantil e as Áreas do Conhecimento do Ensino Fundamental e Ensino Médio. E em terceiro lugar: interpretar essas competências na tentativa de compreender como ocorre a construção do conhecimento científico na Base Nacional Comum Curricular.

5 Primeira versão - out/2015 a mar/2016; segunda versão - publicada em maio/2016. 


\section{RESULTADOSE DISCUSSÃO}

Para a construção dos conhecimentos e também para o desenvolvimento de habilidades, valores e atitudes, a BNCC está sustentada por dez competências gerais que promovem a inter-relação de todos os componentes curriculares ao longo das etapas, em oposição a aprendizagem fragmentada dos conteúdos e promoção à aplicação dos mesmos em sua vida real. Para a BNCC, a ideia geral para competências é:

[...] é definida como a mobilização de conhecimentos (conceitos e procedimentos), habilidades (práticas, cognitivas e socioemocionais), atitudes e valores para resolver demandas complexas da vida cotidiana, do pleno exercício da cidadania e do mundo do trabalho. (BNCC, 2019, p. 16).

Então, compreende-se que o foco nas competências para a construção dos conhecimentos, vem reafirmar sobre o que os estudantes devem saber e o mais importante sobre o que saber fazer como produto de sua aprendizagem escolar.

Dentre a dez competências gerais propostas pela BNCC, pode-se destacar seis competências mais direcionadas ao conhecimento científico, sendo elas: competências 1, 2, 4, 5, 7 e 10.

Tais competências apresentam:

(a) a valorização da construção histórica do conhecimento;

(b) o exercício a curiosidade e utilizar-se das abordagens da Ciência como a reflexão, investigação, formulação de hipóteses e resolução de problemas;

(c) utilização das diferentes linguagens para entender, analisar, expressar e divulgar o conhecimento científico;

(d) articular o acesso e o entendimento para a busca de conhecimentos armazenados em tecnologias digitais de modo a compreender o uso e acesso a essas informações;

(e) argumentação com base em fatos e dados confiáveis sempre com ética em posicionamentos;

(f) tomada de decisões no âmbito pessoal e coletivo com autonomia, responsabilidade, pautados nos conhecimentos construídos na escola, direcionados pela ética, democracia, sustentabilidade, inclusão e solidariedade.

Ao delinear tais competências, a BNCC: “Assume que a educação deve afirmar valores e estimular ações que contribuam para a transformação da sociedade, tornando-a mais humana, socialmente justa e, também voltada para a preservação da natureza" (BRASIL, 2013, p.).

Busca-se então, neste momento, compreender nas seis competências destacadas, as características explícitas e implícitas para a construção do conhecimento científico ao longo da Educação Básica. A competência 1, é a primeira a trazer as características da ciência, a mesma nos impulsiona à

Valorizar e utilizar os conhecimentos historicamente construídos sobre o mundo físico, social e cultural para entender e explicar a realidade (fatos, informações, fenômenos e processos linguísticos, culturais, sociais, econômicos, científicos, tecnológicos e naturais), colaborando para a construção de uma sociedade solidária. (BNCC, 2018, p. 18). 
Ao analisar-se esta competência, a BNCC nos remete para a revelação da ciência aos estudantes como um processo, não como um produto acabado na forma de teoria e modelos, deve mostrar seu caráter dinâmico e perecível de seus saberes.

Paixão e Cachapuz (2003), corroborando com esta ideia, acreditam que o conhecimento científico deve ser compreendido como um construto de homens e mulheres ao longo de sua trajetória, distanciando-se então tal construção das correntes empiristas, racionalistas e positivistas das ciências, afastando os modelos lógicos, ascendendo os modelos históricos e seus contextos de produção.

A promoção da Ciência, considerando então, seu processo de construção, deixa de lado uma concepção arbitrária, pois são situados historicamente, destacando seus aspectos econômicos, políticos e sociais que tornaram possíveis e indispensáveis as discussões teóricas e experimentais.

A competência 2, é a segunda competência a nos trazer características para a construção das ciências, apoiada nas etapas que consiste o método científico, não rigoroso, mas o método que valoriza as atividades de imaginação e criatividade, em contraposição a uma construção atemporal, não humanista e definitiva das ciências. Esta competência nos remete à

Exercitar a curiosidade intelectual e recorrer à abordagem própria das ciências, incluindo a investigação, a reflexão, a análise crítica, a imaginação e a criatividade, para investigar causas, elaborar e testar hipóteses, formular e resolver problemas e inventar soluções com base nos conhecimentos das diferentes áreas. (BNCC, 2017, p. 18).

A concepção de ciências como possuidora de poder sobre a nossa sociedade, construída a partir de observações e experimentações para uma coleta de dados metódica e adequada para formulação de leis e princípios, tidos como verdade científica, sempre foi amplamente divulgada e ensinada.

Para Lopes (1999) as visões de ciências constituídas em bases empíricas, em que suas verdades são inquestionáveis, apontadas somente por fatos e experimentações, sem levar em consideração, as características de imaginação, criatividade e dúvida que devem permear o método científico, divulgam uma visão dominante das ciências.

A competência 4, é a terceira competência a nos trazer características para a construção das ciências, é preciso saber identificar nas diferentes linguagens a expressão do conhecimento e partir delas construir sua visão de mundo e com isso determinar a melhor forma de divulgar esse conhecimento acumulado, isso é possibilitado ao

Utilizar diferentes linguagens - verbal (oral ou visual-motora, como Libras, e escrita), corporal, visual, sonora e digital -, bem como conhecimentos das linguagens artística, matemática e científica, para se expressar e partilhar informações, experiências, ideias e sentimentos em diferentes contextos e produzir sentidos que levem ao entendimento mútuo. (BNCC, 2018, p. 9).

Essa competência favorece o desenvolvimento da linguagem e juntamente com isso a compreensão das diferentes manifestações que eles têm contato no seu cotidiano, para analisar essas infor-

Interfaces Científicas - Educação • Aracaju • V.9 • N.1 • p. 107-118 • 2020 • Número Temático - Políticas Públicas Educacionais 
mações de forma crítica e construtiva, além disso podem criar uma imagem de mundo que facilite a compreensão dos fenômenos que ocorrem a sua volta. Em um segundo momento o desenvolvimento da capacidade de comunicação acaba por potencializar a divulgação científica, sendo essa uma parte da evolução da ciência e a comunicação é fator determinante para que esse conhecimento avance.

Segundo Albagli (1996) essa divulgação pode ocorrer por meio de mídias, museus e centros de ciências, onde o fundamental é a comunicação com o público, utilizando as diversas formas de linguagem para se comunicar e conectar com seu público alvo.

A competência 5, é a quarta competência a nos trazer características para a construção das ciências, ela se torna fundamental para a pesquisa no atual cenário tecnológico que os alunos estão inseridos, pois além de entender as diferentes linguagens que o conhecimento pode se apresentar, podem facilitar o acesso e a utilização das tecnologias digitais da informação, para que possam

Compreender, utilizar e criar tecnologias digitais de informação e comunicação de forma crítica, significativa, reflexiva e ética nas diversas práticas sociais (incluindo as escolares) para se comunicar, acessar e disseminar informações, produzir conhecimentos, resolver problemas e exercer protagonismo e autoria na vida pessoal e coletiva. (BNCC, 2018, p. 9).

Segundo De Almeida (2011) as Tecnologias Digitais de Informação e Comunicação (TDIC) pode sem aliadas na educação para que os estudantes passem a conectar seu mundo de interesse ao mundo do conhecimento, com isso possibilitar a pesquisa e aumento desse conhecimento para a produção científica.

Além disso essa competência acaba por desenvolver nos estudantes um pensamento crítico sobre essa informação, para que saiba discernir sobre quais informações são reais e úteis para seu objetivo, criando assim, também, um letramento digital, ou seja, consiga ser capaz de pesquisar, analisar e selecionar essas informações que lhe são úteis no meio digital.

É importante que todos nós segundo De Almeida (2011), tomemos uma posição crítica e reflexiva diante das informações do meio digital, pois atualmente o acesso a informação e a produção de conhecimento é muito ágil, da mesma forma a quantidade de conteúdo prejudicial também é veloz.

A competência 7, é a quinta competência a nos trazer elementos para a construção do conhecimento científico e valoriza a formulação do conhecimento para à tomada de decisões dos estudantes que estão inseridos em uma comunidade. Essas decisões devem estar pautadas nos contextos sociais e ambientais. Esta competência nos evidencia a importância de

Argumentar com base em fatos, dados e informações confiáveis, para formular, negociar e defender ideias, pontos de vista e decisões comuns que respeitem e promovam os direitos humanos e a consciência socioambiental em âmbito local, regional e global, com posicionamento ético em relação ao cuidado de si mesmo, dos outros e do planeta (BNCC, 2018, p. 19).

A construção do conhecimento no âmbito escolar deve ter por finalidade promover a formação dos estudantes voltada para um posicionamento crítico perante as situações de seu cotidiano e para ser exercício da cidadania (SANTOS; MORTIMER, 2009). 
A atuação na sociedade requer tomada de decisões e atitudes pautadas em valores atrelados não só ao seu próprio interesse, mas também aos interesses do coletivo, valores estes destacados por Santos e Mortimer (2000, p.) "[...] como os de solidariedade, fraternidade, compromisso social, reciprocidade, respeito ao próximo e de generosidade”. A compreensão e discussão desses valores levarão os estudantes a obter uma formação para o exercício da cidadania crítica e empenhar-se com a sociedade de maneira ampla e reflexiva.

A competência 10, é a última que nos traz componentes para a construção do conhecimento científico, destaca como as ações e as tomadas de decisões dos estudantes, como cidadãos situados em uma sociedade, devem ser não apenas singular, pessoal, mas também no plural, utilizando os conhecimentos adquiridos em todas as áreas do conhecimento, sempre pautados pelos princípios da ética. Esta competência mostra como é relevante

Agir pessoal e coletivamente com autonomia, responsabilidade, flexibilidade, resiliência e determinação, tomando decisões, com base nos conhecimentos construídos na escola, segundo princípios éticos democráticos, inclusivos, sustentáveis e solidários (BNCC, 2018, p. 19).

Para a melhor compreensão e articulação dos conhecimentos mediados ao longo da vida escolar, é necessário o abandono de práticas de ensino e aprendizagem que valorizam a repetição e a acumulação de conhecimentos. A desvalorização de aspectos conceituais das ciências e a desvinculação com a história da sociedade tem sido uma realidade no ensino delas.

É compreensível a preocupação com os processos de ensino de aprendizagem no ensino das ciências e sua divulgação científica, pois como defende Lopes (1999) a não formação enciclopédica para compreender os avanços das ciências, mas a formação de uma visão contemporânea, pronta para mudanças e questionamentos.

Ainda para Lopes (1999) a formação científica nos dias atuais, deve tencionar os cidadãos, o real alcance sobre um avanço científico divulgado pela mídia, permitindo a interpretação e uma postura crítica sobre as divulgações científicas, compreensão que só pode ser possível quando se entendem que o mundo exige uma racionalidade construída por nós, cidadãos, descontínua e plural, portanto, passível de alterações.

Entende-se, então, que a organização dos componentes curriculares, sustentados pelas competências gerais, pode promover a construção dos conhecimentos de forma ampla e aplicável para os estudantes.

Para a construção dos conhecimentos científicos, ancorados nas competências já listadas, a articulação entre os ciclos é imprescindível para a construção deles.

$\mathrm{Na}$ Educação Infantil, as atividades de aprendizagem devem ser organizadas para o estímulo de atitudes de curiosidade, questionamento, investigação e encantamento. Para o desenvolvimento de tais atividades, deve-se romper com as concepções de assistencialismo e escolarização atribuídas para esta etapa da Educação Básica. De acordo com as Diretrizes Curriculares Nacionais para a Educação Infantil [DCNEI], definem a criança como "Um sujeito histórico e de direitos, que brinca, imagina, fantasia, deseja, aprende, observa, experimenta, narra, questiona e constrói sentidos a natureza e sobre a sociedade, produzindo cultura" (BRASIL, 2009, p.). 
Por produzir conhecimento e cultura por meio das várias atividades que a criança desempenha, deve-se promover o acesso a processos de apropriação, renovação e articulação entre saberes e conhecimentos. Para a articulação de tais processos, a Educação Infantil vem organizada em seis direitos de aprendizagem e desenvolvimento, sendo eles: conviver, brincar, participar, explorar, expressar e conhecer para que haja o aprendizado e o progresso das crianças ao longo desta etapa.

O desenvolvimento dos direitos de aprendizagem ao longo da Educação Infantil está organizado por Campos de Experiências: “O eu, o outros e o nós”, "Corpo, gestos e movimentos”, "Traços, sons, cores e formas", "Oralidade e escrita”, "Espaços, tempos, quantidades, relações e transformações” que visam a ludicidade e a interação na construção dos conhecimentos, o surgimento dos questionamentos, observações e investigações mediadas pelo professor, para potencializar as experiências atreladas às diversas naturezas.

Ao longo dos nove anos que integram o Ensino Fundamental, o conhecimento está dividido em quatro áreas do conhecimento, sendo elas: (1) Linguagens, constituída pelos componentes curriculares: Língua Portuguesa, Arte, Educação Física e Língua Inglesa para os anos finais; (2) Matemática, composta por um único componente curricular: Matemática; (3) Ciências da Natureza, também composta por apenas um componente curricular: Ciências e (4) Ciências Humanas, formada pelos componentes curriculares: História e Geografia. As quatro áreas do conhecimento farão a inter-relação entre os diversos conhecimentos e saberes contidos nos diferentes componentes curriculares, sempre preservando a particularidade de cada componente curricular.

Para a articulação dos conhecimentos científicos ao longo do Ensino Fundamental, tanto as áreas do conhecimento quanto os componentes curriculares estão ancorados em competências específicas da área e de cada componente curricular e tais competências estão em consonância com as dez competências gerais já citadas neste estudo.

Além das competências, a organização do conhecimento pode ser feita por unidades temáticas que contemplam os objetos de conhecimento, os quais estão relacionadas as várias habilidades que deverão ser desenvolvidas em cada unidade temática ao longo dessa etapa escolar.

No Ensino Fundamental, anos iniciais, deve-se articular atividades que estimulem a exploração e a compreensão de processos naturais e sociais. Já no Ensino Fundamental, anos finais, a contextualização, a articulação interdisciplinar e a utilização de recursos matemáticos em contextos das ciências naturais deve permear toda a construção do conhecimento científico.

O Ensino Médio é considerado a etapa final da educação básica, porém se torna necessário garantir a permanência do querer aprender, para que a demanda de novos conhecimentos presente nesse mundo globalizado seja alcançada, se ao decorrer dessa etapa de ensino o estudante conseguir desenvolver essas competências esperadas ao final do processo, ele estará apto para que possa ser inserido na sociedade.

A etapa se preocupa em articular a preparação para o trabalho, a cidadania e os fundamentos científico-tecnológicos, levando em conta o que ela chama de projeto de vida, isso significa que o estudante estará apto a decidir o que espera do futuro, traçar um objetivo e utilizar as competências que forem necessárias para o processo. 
Para contemplar tais ações, múltiplos recursos didáticos e estratégias devem ser utilizados para promover o encantamento, o desafio e a motivação para o questionamento. O lúdico, recursos tecnológicos, construção de modelos e exemplificações, investigações práticas e conceituais devem permear a construção da ciência pelos estudantes, sempre respeitando a maturidade de cada etapa/ano.

\section{CONSIDERAÇÕES FINAIS}

O estudo realizado buscou compreender como ocorre a construção do conhecimento científico na Base Nacional Comum Curricular, documento que traz diretrizes para a (re) organização da Educação Básica, da Educação Infantil ao Ensino Médio, apoiada em documentos já vigentes como a LDB, DCNEI, Caderno de Educação em Direitos Humanos entre outros documentos oficiais que regem nosso país.

A BNCC organiza a construção do conhecimento para todos os ciclos a partir das competências gerais que inter-relacionam as várias áreas do conhecimento, valorizando a mediação dos conteúdos dentro de cada componente curricular de forma interdisciplinar, não fragmentada, visando uma formação integral dos estudantes.

\section{REFERÊNCIAS}

ALBAGLI, S. Divulgação científica: informação científica para cidadania. Ciência da informação, v. 25, n. 3, 1996.

BRASIL. Constituição 1988. Constituição da República Federativa do Brasil. Brasília, DF: Senado Federal: Centro Gráfico, 1988.

BRASIL. Lei número 9394, 20 de dezembro de 1996. Lei de Diretrizes e Bases da Educação Nacional, 1996.

BRASIL. Conselho Nacional de Educação. Câmara de Educação Básica. Resolução nº 5, de 17 de dezembro de 2009. Fixa as Diretrizes Curriculares Nacionais para a Educação Infantil, 2009.

BRASIL. Secretaria de Direitos Humanos da Presidência da República. Caderno de Educação em Direitos Humanos. Educação em Direitos Humanos: Diretrizes Nacionais. 2013.

BRASIL. Ministério da Educação. Base nacional comum curricular. Brasília, DF: MEC, 2018.

Disponível em: basenacionalcomumcurricular.mec.gov.br. Acesso em: 26 jul. 2019.

DE ALMEIDA, M. E. B.; da SILVA, M. D. G. M. Currículo, tecnologia e cultura digital: espaços e tempos de web currículo. Revista e-curriculum, v. 7, n. 1, 2011. 
GAGLIARDI, R. Cómo utilizar la historia de las ciencias em la enseñanza de las ciencias. Enseñanza de las Ciencias, v. 6, n. 3, p. 291-296, 1988.

GAGLIARDI, R.; GIORDAN, A. La historia de las ciencias: una herramienta para la enseñanza. Enseñanza de las Ciencias, v. 4, n. 3, p. 253-258, 1986.

LOPES, A. C. Conhecimento escolar: ciência e cotidiano. Rio de Janeiro-RJ: UERJ, 1999.

MATTHEWS, M. R. História, filosofia e ensino de ciências: a tendência atual de reaproximação. Caderno Catarinense de Ensino de Física, Florianópolis, v. 12, n. 3, p. 164-214, dezembro 1995.

PAIXÃO, M. F.; CACHAPUZ, A. Mudanças na prática de ensino de química pela formação dos professores em história e filosofia das ciências. QNEs, v. 18, p. 31-36, 2003.

RODRÍGUEZ, R. Y. A.; ADÚRIZ-BRAVO, A. A qué epistemología recurrir para investigar sobre la enseñanza de las ciencias. Revista EDUCyT, v. 3, p. 3-16, jan.-jun. 2011.

SANTOS, W. L. P.; MORTIMER, E. F. Uma análise de pressupostos teóricos da abordagem C-T-S (CiênciaTecnologia-Sociedade) no contexto da educação brasileira. Rev. Ensaio, v. 2, p. 110-132, 2000.

SANTOS, W. L. P.; MORTIMER, E. F. Abordagem de aspectos sociocientíficos em aulas de ciências: possibilidades e limitações. Investigações em Ensino de Ciências, v. 14, p. 191-218, 2009. 
1 Doutoranda em Química pela Universidade Federal de São Carlos - UFSCar; Professora da Rede Estadual de Ensino de São Paulo. E-mail: flavia_pierrotti@yahoo.com.br

2 Mestre em Ensino em Química pela Universidade Federal de São Carlos - UFSCar; Professor da Rede Estadual de Ensino de São Paulo. E-mail: marcos199697@gmail.com

3 Doutor em Educação Escolar pela Faculdade de Ciências e Letras de Araraquara; Pós-Doutor em Ciências Sociais UNESP/Marília; Professor do Programa de Pós-Graduação em Políticas Públicas da Universidade de Mogi das Cruzes - UMC e do Programa em Gestão e Desenvolvimento Regional pelo Centro Universitário do Sul de Minas - UNIS. E-mail:r.silva@unesp.br

4 Doutora em Educação Escolar Faculdade de Ciências e Letras de Araraquara e em Química pelo Instituto de Química de Araraquara - Unesp; Professora da Escola Superior de Agricultura "Luiz de Queiróz", Universidade de São Paulo - ESALQ/USP. E-mail: rosebelly.esalq@usp.br

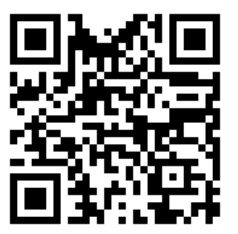

A autenticidade desse artigo pode ser conferida no site https://periodicos. set.edu.br

\section{(ㅇ) (1) (-)}

Este artigo é licenciado na modalidade acesso abertosob a Atribuição-Compartilha Igual CC BY-SA

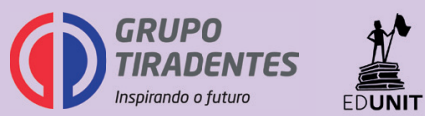

